\title{
Omitting antagonism of neuromuscular block: effect on postoperative nausea and vomiting and risk of residual paralysis. A systematic review
}

\author{
M. R. Tramèr ${ }^{1 *}$ and T. Fuchs-Buder ${ }^{2}$ \\ ${ }^{1}$ Divison of Anaesthesiology, Department APSIC, Geneva University Hospital, CH-1211 Geneva 14, \\ Switzerland. ${ }^{2}$ Department of Anaesthesiology, University of Saarland, D-66421 Homburg/Saar, Germany \\ *To whom correspondence should be addressed
}

\begin{abstract}
We have estimated the effect of omitting antagonism of neuromuscular block on postoperative nausea and vomiting. A systematic search (MEDLINE, EMBASE, Biological Abstracts, Cochrane library, reference lists and hand searching; no language restriction, up to March 1998) was performed for relevant randomized controlled trials. In eight studies ( I I 34 patients), antagonism with neostigmine or edrophonium was compared with spontaneous recovery after general anaesthesia with pancuronium, vecuronium, mivacurium or tubocurarine. On combining neostigmine data, there was no evidence of an antiemetic effect when it was omitted. However, the highest incidence of emesis with neostigmine $1.5 \mathrm{mg}$ was lower than the lowest incidence of emesis with $2.5 \mathrm{mg}$. Numbers-needed-to-treat to prevent emesis by omitting neostigmine compared with using it were consistently negative with $1.5 \mathrm{mg}$, and consistently positive (3-6) with $2.5 \mathrm{mg}$. There was a lack of evidence for edrophonium. In two studies, three patients with spontaneous recovery after mivacurium or vecuronium needed rescue anticholinesterase drugs because of clinically relevant muscle weakness (number-needed-to-harm, 30). Omitting neostigmine may have a clinically relevant antiemetic effect when high doses are used. Omitting antagonism, however, introduces a non-negligent risk of residual paralysis even with short-acting neuromuscular blocking agents.
\end{abstract}

Br J Anaesth 1999; 82: 379-86

Keywords: vomiting, nausea; vomiting, incidence; antagonists neuromuscular block, neostigmine; antagonists neuromuscular block, edrophonium; neuromuscular block, antagonism; anaesthesia, audit

Accepted for publication: October 19, 1998

It has been suggested that antagonism of residual neuromuscular block with a mixture of neostigmine and atropine at the end of surgery increases the risk of postoperative nausea and vomiting (PONV). ${ }^{1}$ As a consequence, omitting antagonism of neuromuscular block would decrease the incidence of PONV. However, results from randomized controlled trials (RCT) are contradictory. In one trial, omitting neostigmine at the end of surgery had a statistically significant beneficial effect on PONV. ${ }^{2}$ In another, neostigmine did not influence the risk of PONV. ${ }^{3}$ Authors of yet another study suggested that neostigmine may actually have antiemetic properties. ${ }^{4}$

The aim of this quantitative systematic review was to test the evidence that antagonism of neuromuscular block at the end of surgery influences the incidence of PONV, and to evaluate the likelihood of harm when antagonism was omitted.

\section{Methods}

\section{Inclusion criteria}

We included published full reports of RCT which investigated the effect of spontaneous recovery of neuromuscular block (i.e. antagonism was omitted, experimental group) compared with the same anaesthetic but with active antagonism of neuromuscular block with anticholinesterase drugs (control group). Spontaneous recovery of neuromuscular block was assumed when patients received a placebo or no treatment. Relevant trials had to report dichotomous data (presence or absence of an event) on PONV or adverse events.

\section{Systematic search and validity score}

We searched systematically for relevant reports in MEDLINE (from 1966), Biological Abstracts (from 1966), 
EMBASE (from 1980) and Cochrane Library (1998, issue I) (date of last electronic search March 20, 1998). The searches were with combinations of the free text terms 'nausea, vomiting, emesis, neostigmine, prostigmine, edrophonium, antagonism and neuromuscular block'. Reference lists of retrieved reports and review articles were checked. Locally available anaesthesia journals were hand-searched. The search was not restricted to the English language. Abstracts were not considered. Authors were contacted by letter when there was ambiguity about data. Each retrieved report was read by both authors independently to assess adequacy of randomization and blinding, and description of withdrawals using the validated three-item, 5-point Oxford score. ${ }^{5}$ Reports which were described as 'randomized' were given 1 point, and another point if the method of randomization was described and adequate (such as a table of random numbers). Randomization was assumed when stated as such in the report. One point was given when the study was described as 'double-blind'. When the method of double-blinding was described and adequate (identical ampoules, for instance), another point was given. Finally, reports which described the number and reasons for withdrawals were given 1 point. Thus the maximum score of an included randomized controlled trial was 5 and the minimum score was 1 . We compared the allocated scores and resolved differences by discussion.

\section{Data extraction}

We obtained information on patients, anaesthetic, type and dose of anticholinesterase drugs, controls, surgery, study end-points and intervention-related adverse effects from each included report. Only dichotomous data on efficacy and harm were extracted. Relevant efficacy data were prevention of early emetic events (cumulative incidence nearest to $6 \mathrm{~h}$ after surgery) and prevention of late emetic events (cumulative incidence nearest to $48 \mathrm{~h}$ ). A maximum of three different emetic events were extracted from each trial, for both early and late: nausea, vomiting (including retching) and any emetic event (nausea, vomiting, or nausea and vomiting). Events were treated separately.

Dichotomous data on clinically diagnosed adverse events related to omitting antagonism were extracted as described in the original reports. Clinically overt muscle weakness was such an end-point. Data on neuromuscular monitoring (train-of-four ratio, for instance) were not considered.

\section{Quantitative analysis (meta-analysis)}

For individual and combined trials, the relative antiemetic benefit of omitting antagonism was calculated as relative risk with $95 \%$ confidence intervals $(\mathrm{CI}){ }^{6}$ A random effects $\operatorname{model}^{7}$ was used to combine data. The random effects model incorporates both within- and between-study variance, and yields a more conservative estimate of treatment effect when there is variability in results. A statistically significant difference between intervention (omitting antagonism) and control (giving an anticholinesterase drug) was assumed when the $95 \%$ confidence interval of the relative risk did not include 1.

Numbers-needed-to-treat were calculated. ${ }^{8}$ We decided to calculate $95 \% \mathrm{CI}$ around the number-needed-to-treat point estimate ${ }^{9}$ only when the relative risk indicated a statistically significant difference between intervention and control (because then the confidence interval around the number-needed-to-treat would not include infinity). A positive number-needed-to-treat indicated how many patients had to be exposed to the intervention (i.e. omitting antagonism) in order to prevent one particular emetic event in one patient, who would have had this event had they received an anticholinesterase drug. Thus a positive number-neededto-treat indicated that omitting anticholinesterase drugs had an antiemetic effect and, therefore, antagonism was emetogenic. According to pre-set criteria, a number-neededto-treat between 1 and 5 was considered as a clinically relevant improvement. ${ }^{10} \mathrm{~A}$ negative number-needed-to-treat indicated less risk of PONV with pharmacological antagonism compared with spontaneous recovery, suggesting that anticholinesterase drugs had an antiemetic effect.

For estimation of the additional risk of interventionrelated adverse effects, we calculated relative risk with $95 \%$ $\mathrm{CI}$ and the number-needed-to-harm, as for number-neededto-treat. ${ }^{11}$ If any cell of a sample was zero, then 0.5 was added to all cells of that sample to calculate the relative risk. Calculations were performed using Excel 5.0 on a Power Macintosh G3.

\section{Results}

\section{Retrieved reports}

Eleven reports were found. Three were subsequently excluded; two had neither a placebo nor a no-treatment group. ${ }^{13-14}$ The third trial did not report any data on PONV or intervention-related harm, ${ }^{15}$ and the original authors were not able to respond to our enquiry to provide relevant data.

\section{Analysed reports}

Eight trials with data on 1134 patients were analysed (Table 1). $.^{2-4} 1216-19$ One trial with a pseudo-randomization (alternans allocation) ${ }^{16}$ was included in the analysis. The median quality score of the RCT was 3 (range 1-4). Mean study size was 142 patients (range 38-464).

Different doses of edrophonium or neostigmine combined with different doses of atropine or glycopyrrolate were compared with placebo or no treatment in children and adults. Neuromuscular blocking agents were pancuronium, tubocurarine, vecuronium and mivacurium. Seven trials reported valid PONV data. ${ }^{2-416-19}$ Observation periods were during patient stay in the post-anaesthetic care unit (PACU) and up to a maximum of $27 \mathrm{~h}$ after surgery. One trial did not report PONV data but reported muscle weakness in patients who did not receive anticholinesterase drugs. ${ }^{12}$ This trial was included in the analysis of interventionrelated harm. 
Omitting antagonism of neuromuscular block and PONV

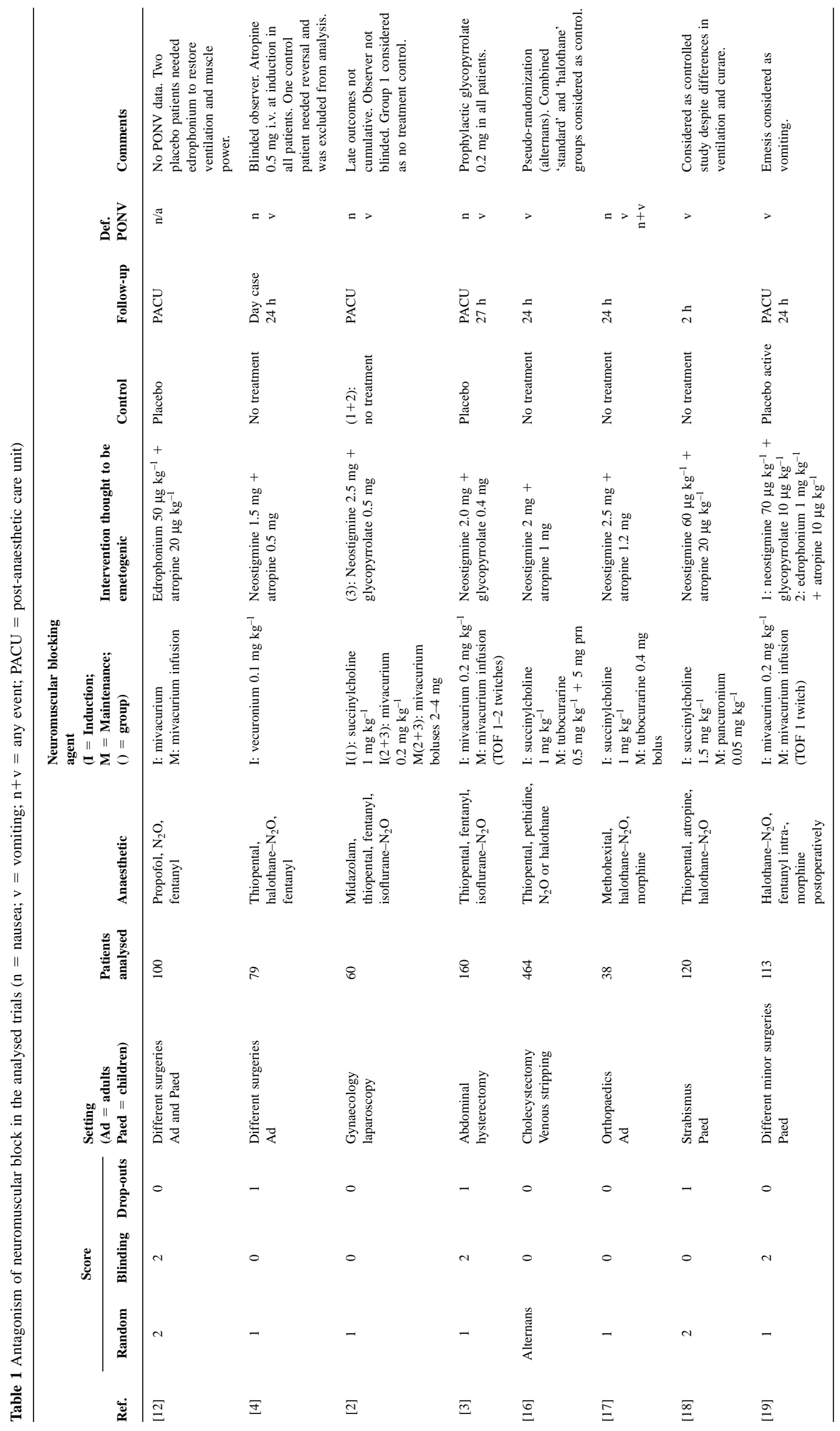


Tramèr and Fuchs-Buder

Table 2 Efficacy of omitting antagonism of neuromuscular block: neostigmine. EER $=$ Experimental event rate (incidence of PONV when antagonism of neuromuscular block is omitted); CER $=$ Control event rate (incidence of PONV with antagonism of neuromuscular block)

\begin{tabular}{|c|c|c|c|c|c|c|c|}
\hline \multirow[b]{2}{*}{$\begin{array}{l}\text { Dose of } \\
\text { neostigmine }\end{array}$} & \multicolumn{4}{|c|}{ No. of patients with outcome/total number of patients } & \multirow[b]{2}{*}{$\begin{array}{l}\text { Relative risk } \\
(95 \% \text { CI })\end{array}$} & \multirow[b]{2}{*}{$\begin{array}{l}\text { Number-needed- } \\
\text { to-treat }\end{array}$} & \multirow[b]{2}{*}{ Ref. } \\
\hline & $\begin{array}{l}\text { Placebo or } \\
\text { no treatment }\end{array}$ & $\operatorname{EER}(\%)$ & Antagonism & CER $(\%)$ & & & \\
\hline \multicolumn{8}{|c|}{ Prevention of early nausea $(0-6 \mathrm{~h})$} \\
\hline $1.5 \mathrm{mg}$ & $23 / 39$ & 41.0 & $29 / 40$ & 27.5 & & & {$[4]$} \\
\hline $2.0 \mathrm{mg}$ & $69 / 80$ & 13.8 & $69 / 80$ & 13.8 & & & [3] \\
\hline $2.5 \mathrm{mg}$ & $27 / 40$ & 32.5 & $7 / 20$ & 65.0 & & & {$[2]$} \\
\hline Combined & $119 / 159$ & 25.2 & $105 / 140$ & 25.0 & $1.04(0.76-1.43)$ & -636 & {$[2-4]$} \\
\hline \multicolumn{8}{|c|}{ Prevention of early vomiting ( $0-6$ h) } \\
\hline $1.5 \mathrm{mg}$ & $28 / 39$ & 28.2 & $34 / 40$ & 15.0 & & & {$[4]$} \\
\hline $2.0 \mathrm{mg}$ & $71 / 80$ & 11.3 & $71 / 80$ & 11.3 & & & [3] \\
\hline $2.5 \mathrm{mg}$ & $29 / 40$ & 27.5 & $11 / 20$ & 45.0 & & & {$[2]$} \\
\hline $60 \mu \mathrm{g} \mathrm{kg}^{-1}$ & $30 / 60$ & 50.0 & $36 / 60$ & 40.0 & & & {$[18]$} \\
\hline $70 \mu \mathrm{g} \mathrm{kg}^{-1}$ & $33 / 37$ & 10.8 & $25 / 38$ & 34.2 & & & [19] \\
\hline Combined & $191 / 256$ & 25.4 & $177 / 238$ & 25.6 & $1.03(0.86-1.22)$ & 417 & {$[2-4,18,19]$} \\
\hline \multicolumn{8}{|c|}{ Prevention of late nausea $(0-27 \mathrm{~h})$} \\
\hline $1.5 \mathrm{mg}$ & $23 / 39$ & 41.0 & $26 / 40$ & 35.0 & & & {$[4]$} \\
\hline $2.0 \mathrm{mg}$ & $57 / 80$ & 28.8 & $52 / 80$ & 35.0 & & & [3] \\
\hline $2.5 \mathrm{mg}$ & $13 / 19$ & 31.6 & $6 / 19$ & 68.4 & & & [17] \\
\hline Combined & $93 / 138$ & 32.6 & $84 / 139$ & 39.6 & $1.11(0.93-1.33)$ & 14 & {$[3,4,17]$} \\
\hline \multicolumn{8}{|c|}{ Prevention of late vomiting $(0-27 \mathrm{~h})$} \\
\hline $1.5 \mathrm{mg}$ & $25 / 39$ & 35.9 & $32 / 40$ & 20.0 & & & {$[4]$} \\
\hline $2.0 \mathrm{mg}$ & $48 / 80$ & 40.0 & $54 / 80$ & 32.5 & & & [3] \\
\hline $2.0 \mathrm{mg}$ & $23 / 82$ & 72.0 & $154 / 382$ & 59.7 & & & {$[16]$} \\
\hline $2.5 \mathrm{mg}$ & $17 / 19$ & 10.5 & $10 / 19$ & 47.4 & & & {$[17]$} \\
\hline $70 \mu \mathrm{g} \mathrm{kg}^{-1}$ & $21 / 37$ & 43.2 & $17 / 38$ & 55.3 & & & [19] \\
\hline Combined & $134 / 257$ & 47.9 & $267 / 559$ & 52.2 & $0.98(0.75-1.28)$ & 23 & {$[3,4,16,17,19]$} \\
\hline
\end{tabular}

\section{Antiemetic efficacy of omitting antagonism of neuromuscular block}

Neostigmine-efficacy data

Neostigmine 60 or $70 \mu \mathrm{g} \mathrm{kg}-1$, and $1.5,2.0$ or $2.5 \mathrm{mg}$ was used in seven trials. When emetic outcomes were combined (i.e. nausea or vomiting separately, both early and late) across all trials and all neostigmine doses, there was neither a statistically significant nor a clinically relevant effect of omitting neostigmine on PONV (Table 2). For all outcomes, $95 \%$ CI of the relative risk included 1 , and numbers-neededto-treat were negative or greater than 10 .

\section{Absolute risk of PONV with placebo or no treatment, and} with neostigmine

Five trials compared three different fixed doses of neostigmine (i.e. $1.5,2.0$ and $2.5 \mathrm{mg}$ ) with placebo or no treatment. ${ }^{2-41617}$ In patients receiving placebo or no treatment, and thus exposed to spontaneous recovery, the absolute risk (incidence) of early nausea and vomiting was $10-40 \%$, and of late nausea and vomiting, 10-70\% (Fig. 1 ). Corresponding values in patients receiving neostigmine $1.5 \mathrm{mg}$ (one trial), $2.0 \mathrm{mg}$ (two trials) or $2.5 \mathrm{mg}$ (two trials) suggested an increased risk of PONV with increasing dose of neostigmine. For both early and late outcomes, the highest incidence of PONV with the lowest dose tested $(1.5 \mathrm{mg})$ did not overlap with the lowest incidence of

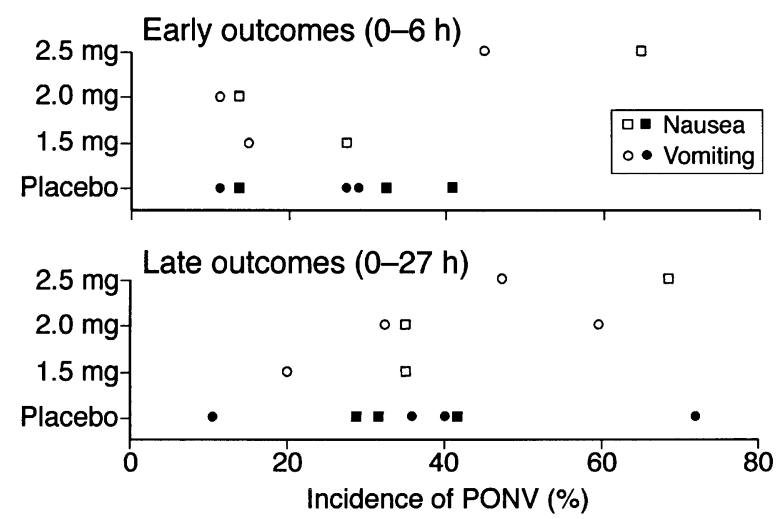

Fig 1 Cumulative incidence of early and late nausea and vomiting with placebo and three different doses of neostigmine in five trials. Symbol size does not take into account trial size.

PONV with the highest dose of neostigmine tested $(2.5 \mathrm{mg})$ (Fig. 1).

Number-needed-to-treat to prevent PONV by omitting neostigmine

In one trial, the lowest dose of neostigmine $(1.5 \mathrm{mg})$ was compared with no treatment in 79 patients. ${ }^{4}$ For all outcomes (i.e. nausea and vomiting, both early and late) numbersneeded-to-treat were negative (Fig. 2), suggesting an antiemetic effect with neostigmine. Two of four results were statistically significant. 


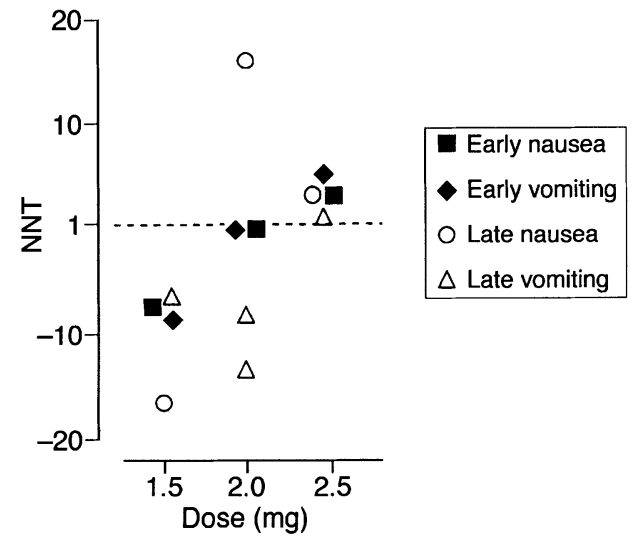

Fig 2 Relationship between dose of neostigmine and the likelihood of PONV in five trials. NNT $=$ Number-needed-to-treat to prevent PONV symptoms by omitting neostigmine in one patient who would have had PONV had they received placebo or no treatment.

Two trials compared the medium dose of neostigmine $(2.0 \mathrm{mg}$ ) with placebo or no treatment in 624 patients (Fig. 2). ${ }^{3} 16$ Results were inconsistent. The numbers-needed-totreat to prevent PONV by omitting neostigmine $2.0 \mathrm{mg}$ ranged from approximately 15 (suggesting an emetogenic effect when using neostigmine, albeit clinically not relevant) to negative values (suggesting an antiemetic effect when using neostigmine). Two of five results were statistically significant.

In two trials, the highest dose of neostigmine tested $(2.5 \mathrm{mg})$ was compared with no treatment in 98 patients (Fig. 2). ${ }^{2} 17$ For all outcomes the numbers-needed-to-treat were positive (3-6), suggesting a clinically relevant emetogenic effect of neostigmine, that is an antiemetic effect when neostigmine at this dose was omitted. Three of four results were statistically significant.

Two trials compared body weight-adjusted doses of neostigmine in 233 children. ${ }^{18}$ In one trial, the incidence of vomiting in children receiving neostigmine $60 \mu \mathrm{g} \mathrm{kg}^{-1}$ was lower compared with children not receiving it. ${ }^{18}$ Accordingly, the number-needed-to-treat to prevent vomiting was negative but the result was not statistically significant (relative risk 0.83 (0.60-1.16)). In the other trial, a larger dose of neostigmine $\left(70 \mu \mathrm{g} \mathrm{kg}^{-1}\right)$ was compared with placebo. ${ }^{19}$ The numbers-needed-to-treat when antagonism was omitted were 4.3 (2.4-19), relative risk $1.36(1.05-1.75)$ for early outcomes, and 8.3 , relative risk $1.27(0.81-1.99)$ for late outcomes. These data suggested a clinically relevant emetogenic effect with the higher dose of neostigmine in the immediate postoperative period but not thereafter.

\section{Edrophonium-efficacy data}

One trial investigated the effect of omitting edrophonium $1 \mathrm{mg} \mathrm{kg}^{-1}$ on PONV in 38 children and reported PONV data. ${ }^{19}$ Omitting edrophonium had no beneficial effect on early emesis (relative risk 1.09 (0.91-1.32), number-neededto-treat 13), or on late emesis (relative risk 1.27 (0.811.99), number-needed-to-treat 8).

\section{Harm related to omitting antagonism of neuromuscular block}

Two trials reported clinically relevant muscle weakness in the immediate postoperative period in three of 90 patients who had received placebo ${ }^{4} 12$ but in none of 90 patients who had received edrophonium or neostigmine (Table 3). All three patients needed rescue anticholinesterase drugs to restore ventilation and muscle power. In one of these trials, surgical paralysis was achieved with a single dose of vecuronium $0.1 \mathrm{mg} \mathrm{kg}^{-1}$ at induction. ${ }^{4}$ In the other trial, mivacurium $0.2 \mathrm{mg} \mathrm{kg}^{-1}$ was used to facilitate intubation and a mivacurium infusion during surgery was set to achieve a train-of-four response of 1-2 twitches. ${ }^{12}$ The other trials did not report presence or absence of such adverse events.

Based on data from these two trials, the number-neededto-harm point estimate to produce one patient with clinically relevant muscle weakness by omitting neostigmine or edrophonium compared with giving these drugs was 30 (Table 3 ).

\section{Discussion}

In theory, different mechanisms could be responsible for an increased risk of PONV with the use of anticholinesterase drugs. For instance, a combination of atropine and neostigmine was shown to decrease lower oesophageal sphincter pressure in men. ${ }^{20}$ Also, anticholinesterase drugs have antimuscarinic effects on the gastrointestinal tract which increase motility and stimulate secretion of gastric fluid and acid. Because these effects are partly prevented by anticholinergic drugs, such as atropine, it was suggested that omitting antagonism of neuromuscular block decreases the risk of PONV because anticholinergic drugs are given concomitantly with antagonism. ${ }^{21}$ Finally, in healthy volunteers, intrathecal neostigmine caused severe nausea and vomiting in a dose-dependent manner. ${ }^{22}$ These authors suggested that the most likely site of this adverse effect was in the brainstem. A similar, dose-dependent emetogenic effect with intrathecal neostigmine was found in women undergoing Caesarean section. ${ }^{23}$ The relevance of this, when anticholinesterase drugs are administered systemically, is not known.

Our aim was to test the evidence that antagonism of neuromuscular block at the end of surgery influences the incidence of PONV, and to evaluate the likelihood of harm when antagonism was omitted. However, only a limited number of patients have been tested in these systematically searched trials. Therefore, caution must be exercised in interpreting the results. For instance, it may not be justifiable to attempt dose-response relationships with such a small number of patients.

There is widespread belief that anticholinergic drugs (atropine, glycopyrrolate), which are regularly administered together with anticholinesterase drugs, decrease the risk of PONV. However, there is no substantial evidence to support this view. In RCT, no difference in the incidence of PONV has been shown with atropine or glycopyrrolate compared 
Table 3 Insufficient muscle power on awakening requiring rescue antagonism

\begin{tabular}{|c|c|c|c|c|c|}
\hline \multirow[b]{2}{*}{$\begin{array}{l}\text { Neuromuscular } \\
\text { blocking agent }\end{array}$} & \multicolumn{3}{|c|}{ No. of patients with adverse event/total No. of patients } & \multirow[b]{2}{*}{$\begin{array}{l}\text { Number-needed- } \\
\text { to-Harm }\end{array}$} & \multirow[b]{2}{*}{ Ref. } \\
\hline & $\begin{array}{l}\text { Placebo or } \\
\text { no treatment }\end{array}$ & Antagonism & $\begin{array}{l}\text { Relative risk } \\
(95 \% \text { CI })\end{array}$ & & \\
\hline Mivacurium & $2 / 50$ & $0 / 50$ & & & [12] \\
\hline Vecuronium & $1 / 40$ & $0 / 40$ & & & {$[4]$} \\
\hline Combined & $3 / 90$ & $0 / 90$ & $4.00(0.46-35.1)$ & 30 & {$[4,12]$} \\
\hline
\end{tabular}

with placebo. ${ }^{24} 25$ Therefore, whatever limitations caused by the small numbers in these systematically searched controlled trials, we have to assume that any observed effect is most likely due to the absence or presence of anticholinesterase drugs.

There was some evidence that in adults, antagonism of postoperative neuromuscular block with the highest dose of neostigmine $(2.5 \mathrm{mg})$ may increase the risk of PONV. In two $\mathrm{RCT}^{217}$ with almost 100 patients, omitting this high dose of neostigmine at the end of surgery had a consistent, statistically significant antiemetic effect. The combined data suggest that 1 in 3-6 patients exposed to spontaneous recovery of neuromuscular block will not suffer PONV symptoms who would have done so had they received neostigmine $2.5 \mathrm{mg}$, a degree of benefit which may be regarded as clinically relevant. Lower doses of neostigmine either gave inconsistent results $(2.0 \mathrm{mg})$ or even suggested an antiemetic effect $(1.5 \mathrm{mg})$. In addition, the lowest reported incidence of PONV with the highest dose of neostigmine tested in these trials $(2.5 \mathrm{mg})$ did not overlap with the highest incidence of PONV with the lowest dose of neostigmine $(1.5 \mathrm{mg})$. The synthesis of these, although spare, data may be regarded as evidence of dose-responsiveness. This could explain the confusion about antagonism of neuromuscular block and PONV.

\section{Clinical implications}

Benefit vs harm

These efficacy data need to be put into a clinical context. For instance, the benefit of a particular intervention has to be balanced against its potential for harm. Thus the antiemetic benefit when omitting pharmacological antagonism of neuromuscular block has to be weighed against the risk of residual muscle paralysis because antagonism was omitted.

PONV is distressing and interferes with patient comfort, but it never becomes chronic and is almost never lifethreatening. Here, the limiting factor in decision making is likely to be the additional risk caused by muscle paralysis when antagonism is omitted. The main questions are: What is the incidence of residual paralysis?

\section{What is the incidence of residual paralysis?}

Residual muscle weakness can be diagnosed with neuromuscular monitoring (train-of-four ratio, for instance) or clinically. The train-of-four ratio has been regarded as a surrogate end-point. ${ }^{26}$ We did not analyse data on neuromuscular monitoring but extracted data on clinically overt muscle paralysis.

There is evidence that one in 30 patients undergoing surgery with neuromuscular block but not receiving an anticholinergic drug at the end of surgery will show clinically relevant muscle weakness in the immediate postoperative period because of prolonged neuromuscular block (Table 3). There are two problems with this result. First, two trials reported residual muscle paralysis, and six did not. We do not know if residual paralysis occurred in these other trials but was not reported. Second, the result lacks statistical significance (i.e. 95\% CI around the relative risk point estimate includes 1). However, residual paralysis was described only in patients who did not receive anticholinesterase drugs. Also, the result was based on data from systematically searched RCT, thus providing the strongest evidence currently available. The additional risk of residual muscle paralysis when antagonism of neuromuscular block is omitted is of the same magnitude as the additional risk of intraoperative awareness when nitrous oxide is omitted from general anaesthesia. ${ }^{27}$

In one of the two relevant studies, neuromuscular block was achieved with a continuous infusion of mivacurium, a neuromuscular blocking agent with a fast recovery profile, and neuromuscular monitoring was used during operation. ${ }^{12}$ In the second report, a single bolus dose of vecuronium, an intermediate acting neuromuscular blocking agent, was used at induction. ${ }^{4}$ We have to assume that with the use of long-acting neuromuscular blocking agents (pancuronium, for instance), or with repeated doses of intermediateacting neuromuscular blocking agents, or in the absence of adequate neuromuscular monitoring, the additional risk of residual paralysis when antagonism is omitted will be even higher.

\section{What is the clinical relevance of residual paralysis?}

Muscle weakness may lead to hypoventilation with subsequent hypercapnia and hypoxia. Residual paralysis may attenuate the ventilatory response to hypoxia, impairing adequate function of the carotid body. ${ }^{28}$ Residual paralysis impairs coughing, increasing the likelihood of atelectasis. In addition, compromised laryngeal and pharyngeal function could lead to upper airway obstruction or aspiration. ${ }^{29}$ Because residual paralysis reduces the safety margin, spontaneously breathing patients are more vulnerable to specific drug interactions in the immediate postoperative period. ${ }^{30}$ 
Hypoxia, hypercapnia and pulmonary complications, including atelectasis and aspiration, are major health care problems and they may, theoretically, lead to death. The risk of death caused by pulmonary aspiration in the perioperative period was estimated to be very low. ${ }^{31}$ However, in a large RCT comparing different neuromuscular blocking agents in surgical patients using neuromuscular monitoring but not regular antagonism, almost $7 \%$ of patients developed postoperative pulmonary complications caused by residual muscle paralysis. ${ }^{32}$ Thus, unlike PONV, residual muscle paralysis in the postoperative period is not a minor adverse event and should be regarded as potentially very harmful.

The findings of this systematic review have implications for future research. First, no conclusions can be drawn on edrophonium. Second, there was some evidence of dose responsiveness with neostigmine. However, this may be regarded as hypothesis generating only, because the data were sparse. Thus we need large randomized trials testing the evidence that neostigmine has an impact on PONV, and that this effect is dose-dependent. Weight-adjusted doses of neostigmine should be tested to minimize variability. Finally, until the effect of anticholinesterase drugs on PONV can be based on strong evidence, these drugs should be adequately controlled and reported in RCT which investigate efficacy of antiemetic interventions. There is a possibility that anticholinesterase drugs may confound the results of antiemetic trials.

\section{Acknowledgement}

Dr Tramèr is supported by a PROSPER research grant from the Swiss National Science Foundation (Grant No. 3233-051939.97).

\section{References}

I Rabey PG, Smith G. Anaesthetic factors contributing to postoperative nausea and vomiting. Br J Anaesth 1992; 69 (Suppl. I): $40-5 \mathrm{~S}$

2 Ding Y, Fredman B, White PF. Use of mivacurium during laparoscopic surgery: effect of reversal drugs on postoperative recovery. Anesth Analg 1994; 78: 450-4

3 Hovorka J, Korttila K, Nelskylä K, et al. A. Reversal of neuromuscular blockade with neostigmine has no effect on the incidence or severity of postperative nausea and vomiting. Anesth Analg 1997; 85: |359-6|

4 Boeke AJ, De Lange JJ, Van Druenen B, Langemeijer JJM. Effect of antagonizing residual neuromuscular block by neostigmine and atropine on postoperative vomiting. Br J Anaesth 1994; 72: 654-6

5 Jadad AR, Moore RA, Carroll D, et al. Assessing the quality of reports of randomized clinical trials: is blinding necessary? Control Clin Trials 1996; 17: 1-12

6 Morris JA, Gardner MJ. Statistics with confidence-Confidence intervals and statistical guidelines. In: Gardner MJ, Altman DG, eds. Calculating Confidence Intervals for Relative Risk, Odds Ratios, and Standardised Ratios and Rates. London: BMJ Publishing, 1995; 50-63

7 DerSimonian R, Laird N. Meta-analysis in clinical trials. Control Clin Trials 1986; 7: 177-88

8 Laupacis A, Sackett DL, Roberts RS. An assessment of clinically useful measures of the consequences of treatment. $N$ Engl J Med 1988; 3 18: 1728-33

9 Cook RJ, Sackett DL. The number needed to treat: a clinically useful measure of treatment effect. BMJ 1995; 3 I 0: 452-4

10 Tramèr $M$, Moore $A$, McQuay $H$. Propofol anaesthesia and postoperative nausea and vomiting: quantitative systematic review of randomized controlled studies. Br J Anaesth 1997; 78: 247-55

I I McQuay HJ, Moore RA. Using numerical results from systematic reviews in clinical practice. Ann Int Med 1997; I 26: 712-20

I 2 Bevan DR, Kahwaji R, Ansermino JM, et al. Residual block after mivacurium with or without edrophonium reversal in adults and children. Anesthesiology 1996; 84: 362-7

I 3 Huang $\mathrm{CH}$, Wang MJ, Susetio L, et al. Comparison of the combined effects of atropine and neostigmine with atropine and edrophonium on the occurrence of postoperative nausea and vomiting. Ma Tsui Hsueh Tsa Chi (Taiwan) 1993; 31: II3-6

I 4 Naguib M, Abdulatif M, Al-Ghamdi A. Dose-response relationship for edrophonium and neostigmine antagonism of rocuronium bromide (ORG 9426)-induced neuromuscular blockade. Anesthesiology 1993; 79: 739-45

I5 Devcic A, Munshi CA, Ghandi SK, Kampine JP. Antagonism of mivacurium neuromusuclar block: neostigmine versus edrophonium. Anesth Analg 1995; 8I: 1005-9

I6 Janhunen L, Tammisto T. Postoperative vomiting after different modes of general anaesthesia. Ann Chir Gynaecol Fenniae 1972; 6 I: 152-9

17 King MJ, Milazkiewicz R, Carli F, Deacock AR. Influence of neostigmine on postoperative vomiting. $\mathrm{Br} J$ Anaesth 1988; 6I: 403-6

I Walsh C, Smith CE, Ryan B, Polomeno RC, Bevan JC. Postoperative vomiting following strabismus surgery in paediatric outpatients: spontaneous versus controlled ventilation. Can J Anaesth 1988; 35: 31-5

19 Watcha MF, Safavi FZ, McCulloch DA, Tan TSH, White PF. Effect of antagonism of mivacurium-induced neuromuscular block on postoperative emesis in children. Anesth Analg 1995; 80: 713-17

20 Turner DAB, Smith G. Evaluation of the combined effects of atropine and neostigmine on the lower oesophageal sphincter. $\mathrm{Br}$ J Anaesth 1985; 57: 956-9

2I Kenny GNC. Risk factors for postoperative nausea and vomiting. Anaesthesia 1994; 49 (Suppl.): 6-10

22 Hood DD, Eisenach JC, Tuttle R. Phase I safety assessment of intrathecal neostigmine methylsulfate in humans. Anesthesiology 1995; 82: 331-43

23 Krukowski JA, Hood DD, Eisenach JC, Mallak KA, Parker RL. Intrathecal neostigmine for post-cesarean section analgesia: doseresponse. Anesth Analg 1997; 84: 1269-75

24 Klockgether-Radke A, Demmel C, Braun U, Mühlendyck H. Erbrechen und okulokardialer Reflex. Medikamentöse Prophylaxe mit Droperidol und Atropin in Kindern mit Strabismusoperation. Anaesthesist 1993; 42: 356-60

25 Chisakuta AM, Mirakhur RK. Anticholinergic prophylaxis does not prevent emesis following strabismus surgery in children. Paediatr Anaesth 1995; 5: 97-100

26 Kopman AF. Surrogate endpoints and neuromuscular recovery (editorial). Anesthesiology 1997; 87: 1029-3I

27 Tramèr $M$, Moore $A$, McQuay $H$. Omitting nitrous oxide in general anaesthesia: meta-analysis of intraoperative awareness and postoperative emesis in randomized controlled trials. Br J Anaesth 1996; 76: 186-93

28 Eriksson LI. Reduced hypoxic chemosensitivity in partially paralysed man. A new property of muscle relaxants? Acta Anaesthesiol Scand 1996; 40: 520-3

29 Eriksson LI, Sundman E, Olsson R, et al. Functional assessment of 
the pharynx at rest and during swallowing in partially paralyzed humans: simultaneous videomanometry and mechanomyography of awake human volunteers. Anesthesiology 1997; 87: 1035-43

30 Fuchs-Buder T, Tassonyi E. Magnesium sulphate enhances residual neuromuscular block induced by vecuronium. $\mathrm{Br}$ J Anaesth 1996; 76: 565-6
3I Warner MA, Warner ME, Weber JG. Clinical significance of pulmonary aspiration during the perioperative period. Anesthesiology 1993; 78: 56-62

32 Berg H, Viby-Mogensen J, Roed J, et al. Residual neuromuscular block is a risk factor for postoperative pulmonary complications. Acta Anaesthesiol Scand 1997; 41: 1095-103 